\title{
Variability of the Turbulent Kinetic Energy Dissipation along the A25 Greenland-Portugal Transect Repeated from 2002 to 2012
}

\author{
Bruno Ferron, ${ }^{\mathrm{a}}$ Florian Kokoszka, ${ }^{\mathrm{b}}$ Herlé Mercier, ${ }^{\mathrm{a}}$ PASCAle Lherminier, ${ }^{\mathrm{c}}$ \\ THIERRY HUCK, ${ }^{\mathrm{a}}$ AIDA RIOS, ${ }^{\mathrm{d}}$ AND VIRGINIE THIERRY ${ }^{\mathrm{c}}$ \\ ${ }^{a}$ Laboratoire de Physique des Océans, CNRS, UMR 6523 CNRS-IFREMER-IRD-UBO, IFREMER \\ Centre de Brest, Plouzané, France \\ ${ }^{b}$ Laboratoire de Physique des Océans, UBO, UMR 6523 CNRS-IFREMER-IRD-UBO, Brest, France \\ ${ }^{c}$ Laboratoire de Physique des Océans, IFREMER, UMR 6523 CNRS-IFREMER-IRD-UBO, IFREMER \\ Centre de Brest, Plouzané, France \\ ${ }^{d}$ Instituto de Investigaciones Marinas de Vigo, Consejo Superior de Investigaciones Científicas, Vigo, Spain
}

(Manuscript received 17 July 2015, in final form 16 February 2016)

\begin{abstract}
The variability of the turbulent kinetic energy dissipation due to internal waves is quantified using a finescale parameterization applied to the A25 Greenland-Portugal transect repeated every two years from 2002 to 2012. The internal wave velocity shear and strain are estimated for each cruise at 91 stations from full depth vertical profiles of density and velocity. The $2002-12$ averaged dissipation rate $\left\langle\varepsilon_{2002-2012}\right\rangle$ in the upper ocean lays in the range $1-10 \times 10^{-10} \mathrm{~W} \mathrm{~kg}^{-1}$. At depth, $\left\langle\varepsilon_{2002-2012}\right\rangle$ is smaller than $1 \times 10^{-10} \mathrm{~W} \mathrm{~kg}^{-1}$ except over rough topography found at the continental slopes, the Reykjanes Ridge, and in a region delimited by the Azores-Biscay Rise and Eriador Seamount. There, the vertical energy flux of internal waves is preferentially oriented toward the surface and $\left\langle\varepsilon_{2002-2012}\right\rangle$ is in the range $1-20 \times 10^{-10} \mathrm{~W} \mathrm{~kg}^{-1}$. The interannual variability in the dissipation rates is remarkably small over the whole transect. A few strong dissipation rate events exceeding the uncertainty of the finescale parameterization occur at depth between the Azores-Biscay Rise and Eriador Seamount. This region is also marked by mesoscale eddying flows resulting in enhanced surface energy level and enhanced bottom velocities. Estimates of the vertical energy fluxes into the internal tide and into topographic internal waves suggest that the latter are responsible for the strong dissipation events. At Eriador Seamount, both topographic internal waves and the internal tide contribute with the same order of magnitude to the dissipation rate while around the Reykjanes Ridge the internal tide provides the bulk of the dissipation rate.
\end{abstract}

\section{Introduction}

The diapycnal mixing in the interior of the open ocean is generated by a variety of mechanisms. Among the major sources of mechanical energy for the mixing are internal waves forced by tides, winds, or mean flows interacting with topography (Ferrari and Wunsch 2009). All these mechanical energy sources are strongly dependent on time.

Finescale parameterizations of the diapycnal mixing due to the internal waves are nowadays routinely used. They are frequently applied to datasets obtained from a

Corresponding author address: Bruno Ferron, Laboratoire de Physique des Océans, UMR 6523 CNRS-IFREMER-IRD-UBO, IFREMER Centre de Brest, CS 10070, 29280 Plouzané, France. E-mail: bruno.ferron@ifremer.fr unique realization of a transect, which gives us a snapshot of the mixing intensity at the time of the observations. While this approach is certainly important to map the geographical heterogeneity in the distribution of the diapycnal mixing and points toward mechanisms, one can question how representative such snapshots are because generating mechanisms leading to mixing processes are intermittent. Some recent studies used finescale and microscale observations from profilers, gliders, and towed vehicles to quantify the mean mixing and its temporal variability (Moum et al. 2009; Fer et al. 2014; Palmer et al. 2015; Johnston et al. 2011). Most of these studies focused on the upper ocean $(0-500 \mathrm{~m})$. Much less is known about the large-scale variability of the deep ocean mixing from an observation point of view.

In the present paper, we address this question using hydrographic observations from the A25 Greenland-Portugal 


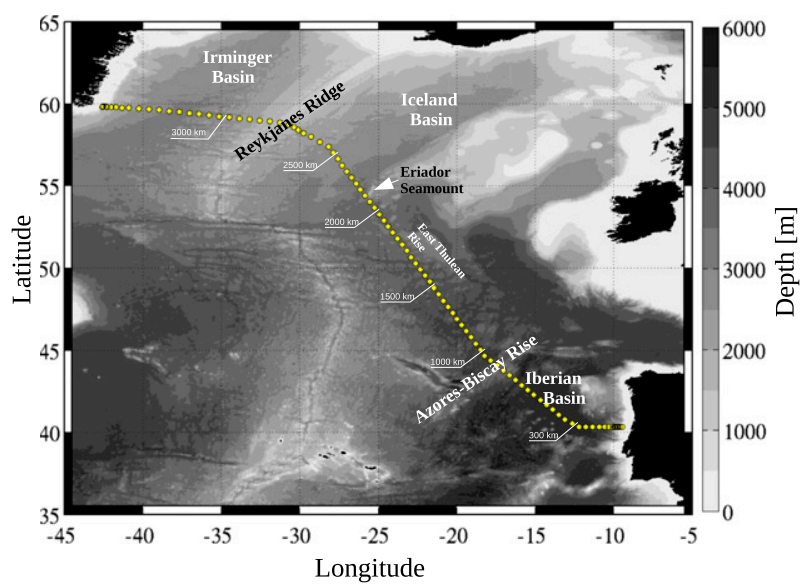

FIG. 1. Positions of the 91 repeated CTD-LADCP stations (yellow dots) along the A25 hydrographic line. This hydrographic line was repeated every 2 years from 2002 to 2012 (see Table 1). Topography from Smith and Sandwell (1997). Some distance-fromPortugal markers $(\mathrm{km})$ are plotted to facilitate the reading of the following figures.

transect that was repeated six times from 2002 to 2012. We examine the variability of the turbulent kinetic energy dissipation due to internal waves in light of some possible generating mechanisms. Section 2 briefly describes the available dataset and some common diagnostics based on velocity and density profiles. Section 3 focuses on the dissipation rate variability, on some characteristics of the internal wave field, and explores the contribution due to the internal tide and topographic internal waves. Results are summarized and discussed in section 4.

\section{Data and methods}

\section{a. Datasets}

\section{1) HYDROGRAPHY}

In this study we used full-depth CTD and loweredADCP (LADCP) vertical profiles of the A25 GreenlandPortugal transect, that was repeated every two years from 2002 to 2012 (Fig. 1). All stations were collected around the same period of the year (late spring to early summer) and over a time span of 3-4 weeks depending on the year (Table 1). For each transect, we selected the 91 stations that were sampled almost systematically. The sensor configuration of the rosette evolved over the years (Table 1). Nevertheless, all LADCP data were processed with the velocity-inversion method initially developed by Visbeck (2002) that provided observations of vertical shear of horizontal currents with a $16-\mathrm{m}$ vertical resolution.

\section{2) TOPOGRAPHY}

Two topographic datasets were used. The first was the 1-min gridded Global Topography version 18.1 (Smith and Sandwell 1997), which resolves scales larger than $10-20 \mathrm{~km}$. It was used to estimate the vertical energy flux into the internal tide. The second was the single beam sounding measured along the transect. It has a horizontal resolution of about $150 \mathrm{~m}$ (depends on ship velocity) and thus correctly resolves topographic scales larger than about $750 \mathrm{~m}$. It was used to estimate the vertical energy flux into topographic internal waves.

\section{3) SEA SURFACE HEIGHT}

To calculate the surface geostrophic eddy kinetic energy, we used the daily global absolute dynamic topography on a $14^{\circ} \times 1 / 4^{\circ}$ horizontal resolution grid. Those fields are produced in delayed time by SSALTO/Duacs and distributed by AVISO.

\section{b. Diagnosed quantities}

\section{1) DISSIPATION RATES FROM VERTICAL SHEAR AND ISOPYCNAL STRAIN VARIANCES}

Estimates of the turbulent kinetic energy dissipation rate associated with the vertical shear of horizontal velocities and with the isopycnal strain generated by the internal wave field were computed using Gregg et al.'s (2003) finescale parameterization:

$$
\varepsilon_{\mathrm{G} 03}=\varepsilon_{0}\left(\frac{N}{N_{0}}\right)^{2} \frac{\left\langle V_{z}^{2}\right\rangle^{2}}{\left\langle V_{z \mathrm{GM}}^{2}\right\rangle^{2}} h\left(R_{\omega}\right) j\left(\frac{f}{N}\right),
$$

where $\varepsilon_{0}=7 \times 10^{-10} \mathrm{~W} \mathrm{~kg}^{-1}$ and $N / N_{0}$ and $\left\langle V_{z}^{2}\right\rangle /\left\langle V_{z \mathrm{GM}}^{2}\right\rangle$ are the buoyancy frequency and the shear variance, respectively, scaled by their respective values from the Garrett and Munk (GM) model (Garrett and Munk 1975; Cairns and Williams 1976). The frequency correction function $h$ reads:

$$
h\left(R_{\omega}\right)=\frac{3}{4}\left(1+\frac{1}{R_{\omega}}\right) \sqrt{\frac{2}{R_{\omega}-1}},
$$

where $R_{\omega}=\left\langle V_{z}^{2}\right\rangle /\left(N^{2}\left\langle\zeta_{z}^{2}\right\rangle\right)$ is the shear $\left(V_{z}\right)$-to-strain $\left(\zeta_{z}\right)$ variance ratio (Polzin et al. 1995). The function $j$ reads

$$
j\left(\frac{f}{N}\right)=\frac{f \cosh ^{-1}(N / f)}{f_{30} \cosh ^{-1}\left(N_{0} / f_{30}\right)},
$$

where $f$ is the inertial frequency and $f_{30}$ its value at a latitude of $30^{\circ}$.

During year 2008, vertical microstructure profiles (VMPs) were collected along with CTD-LADCP profiles 
TABLE 1. Cruise names, years, and periods of each data acquisition and CTD and LADCP settings. The sampling period corresponds to the time taken to carry out the 91 repeated CTD stations of the A25 line. Manufacturer acronyms are: RD Instruments (RDI), Laboratoire de Physique des Océans (LPO), and Sea-Bird Electronics (SBE).

\begin{tabular}{|c|c|c|c|}
\hline Cruise name year & Sampling period & LADCP mounting & CTD mounting \\
\hline \multirow[t]{2}{*}{ Ovide 2002} & 18 June to 10 July & Down-looking RDI $150 \mathrm{kHz}$ & LPO carousel \\
\hline & & Up-looking RDI 300 kHz & Neil Brown Mark III B CTD \\
\hline \multirow[t]{2}{*}{ Ovide 2004} & 11 June to 3 July & Down-looking RDI $150 \mathrm{kHz}$ & LPO carousel \\
\hline & & Up-looking RDI 300 kHz & Neil-Brown Mark III B CTD \\
\hline \multirow[t]{2}{*}{ Ovide 2006} & 25 May to 22 June & Down-looking RDI $150 \mathrm{kHz}$ & LPO carousel \\
\hline & & Up-looking RDI 300 kHz & Neil Brown Mark III B CTD \\
\hline \multirow[t]{2}{*}{ Ovide 2008} & 12 June to 3 July & Down-looking RDI $150 \mathrm{kHz}$ & LPO carousel \\
\hline & & Up-looking RDI $300 \mathrm{kHz}$ & SBE 911plus CTD \\
\hline \multirow[t]{2}{*}{ Ovide 2010} & 10-30 June & Down-looking RDI $150 \mathrm{kHz}$ & LPO carousel \\
\hline & & Up-looking RDI 300 kHz & SBE 911plus CTD \\
\hline \multirow[t]{2}{*}{ Catarina 2012} & 22 June to 23 July & Down-looking RDI $300 \mathrm{kHz}$ & Seabird carousel \\
\hline & & Up-looking RDI $300 \mathrm{kHz}$ & SBE 911plus CTD \\
\hline
\end{tabular}

at 30 stations. A comparison between dissipation rates $\varepsilon_{\mathrm{G} 03}$ estimated from the fine structure and $\varepsilon_{\mathrm{VMP}}$ observed from the microstructure showed that $90 \%$ of $\varepsilon_{\mathrm{G} 03}$ estimates are within a factor of 4 of $\varepsilon_{\mathrm{VMP}}$ values (Ferron et al. 2014). In this paper, we followed exactly the same processing for calculating $\varepsilon_{\mathrm{G} 03}$ as that detailed in Ferron et al. (2014), including the use of 640-m long segments with $75 \%$ overlap. We obtained profiles of 160 -m vertical mean values of $\varepsilon_{\mathrm{G} 03}$ at each CTD-LADCP station and for each transect.

To get some clues about turbulent mechanisms that could possibly explain some of the observed time variability in the dissipation rates, several diagnostics described in the following subsections were computed.

\section{2) ROTARY VELOCITY VARIANCES}

We used ratios of clockwise $(\mathrm{CW})$ to counterclockwise $(\mathrm{CCW})$ velocity variances to estimate the dominant direction of the vertical energy flux of the internal wave field (Gonella 1972; Leaman 1976). The velocity vector of a near-inertial wave rotates $\mathrm{CW}(\mathrm{CCW})$ with depth when the phase propagates upward and the energy downward (upward) in the Northern Hemisphere. A ratio of $\mathrm{CW}$ to $\mathrm{CCW}$ velocity variances above unity is then interpreted as a dominant downward energy flux. This decomposition and interpretation becomes useless for high-frequency waves as they are more linearly polarized than low-frequency waves. Such a decomposition based on velocity spectra emphasizes lower wavenumbers as compared with the shear spectra used to estimate the dissipation rate [Eq. (1)]. Thus, although useful to give us a clue on the internal wave generation, the use of rotary velocity variances does not necessarily describe the waves causing the kinetic energy dissipation. The $\mathrm{CW}$ and $\mathrm{CCW}$ variances were calculated by integrating the rotary spectra on the same vertical segments and same wavenumber band as those used to estimate shear variances for $\varepsilon_{\mathrm{G} 03}$.

\section{3) SPECTRAL Distortion FROM THE GM MODEL}

For estimating $\varepsilon_{\mathrm{G} 03}$, we used the observed shear $\left\langle V_{z}^{2}\right\rangle$ and strain $\left\langle\zeta_{z}^{2}\right\rangle$ variances scaled by their GM counterpart $\left(\left\langle V_{z \mathrm{GM}}^{2}\right\rangle,\left\langle\zeta_{z \mathrm{GM}}^{2}\right\rangle\right)$. To get some indications on the frequency distortion of observed spectra as compared with the GM spectra, we followed Hibiya et al.'s (2012) approach that decomposes the observed shear and strain variances as follows:

$$
\begin{aligned}
\left\langle V_{z}^{2}\right\rangle & =\alpha\left\langle V_{z \mathrm{GM}}^{2}\right\rangle_{2 f-N}+\beta\left\langle V_{z \mathrm{GM}}^{2}\right\rangle_{f-2 f}, \\
\left\langle\zeta_{z}^{2}\right\rangle & =\alpha\left\langle\zeta_{z \mathrm{GM}}^{2}\right\rangle_{2 f-N}+\beta\left\langle\zeta_{z \mathrm{GM}}^{2}\right\rangle_{f-2 f},
\end{aligned}
$$

where $\alpha(\beta)$ is the observed departure from the GM model in the high-frequency $(2 f-N)$ [low-frequency $(f-2 f)]$ band. While $\alpha$ and $\beta$ are measures of the observed spectral levels as compared with the GM model, the ratio $\beta / \alpha$ is a measure of the spectral distortion. Variables $\alpha$ and $\beta$ were calculated on the same vertical segments and same wavenumber band as those used to estimate shear variances for $\varepsilon_{\mathrm{G} 03}$. The shear and strain variances, which are calculated from a limited number of wavenumbers, follow a $\chi_{n}^{2}$ distribution, assuming that the number of degrees of freedom $n$ is equal to twice the number of wavenumbers used in the variance. Their statistical uncertainties follow from this distribution leading to standard deviations in $\alpha$ and $\beta$ of about one.

\section{4) Surface EDDY KINETIC ENERGY}

Geostrophic velocities were computed from the daily absolute dynamic topography from which the 2002-12 mean topography was removed. The eddy kinetic energy (EKE) of the surface geostrophic velocities reads 


$$
\mathrm{EKE}=0.5\left(u_{g}^{2}+v_{g}^{2}\right)
$$

where $u_{g}$ and $v_{g}$ are the zonal and meridional geostrophic velocities. The EKE at the day of a station was interpolated at the station position.

\section{5) BAROTROPIC TO BAROCLINIC TIDAL FLUX}

The barotropic tide to baroclinic internal tide energy flux was estimated using a scale relation derived for subcritical topography (Jayne and St. Laurent 2001) as

$$
F_{\mathrm{IT}}=\frac{1}{2} \rho N_{b} \kappa h^{2} u^{2},
$$

where $\rho$ is the density of seawater, $N_{b}$ is the near bottom buoyancy frequency, $u$ is the barotropic tidal speed, and $(\kappa, h)$ are the characteristic wavenumber and amplitude of the topography. The topography is "subcritical" if the topographic slopes are less than the slope of the internal wave generated by the tides. In the formulation Eq. (2), $\kappa$ is an adjustable parameter (Jayne and St. Laurent 2001; Jayne 2009). As Jayne and St. Laurent (2001) stressed, Eq. (2) is not a precise specification of the internal tide energy flux but results from a scaling approach. To avoid an excessive smearing in the estimated flux (Green and Nycander 2013), $h$ was calculated as $h(x, y)=$ $L(x, y) S_{\max }(x, y)$, where $S_{\max }$ is the maximum slope over a distance $L$ bounded by a maximum of $20 \mathrm{~km}$ around a given position $(x, y)$. The effect of rotation is taken into account by multiplying Eq. (2) by $\left(1-f^{2} / \omega^{2}\right)^{1 / 2}$, where $\omega$ is the tidal frequency (Llewellyn Smith and Young 2003; Nycander 2005). Thus, Eq. (2) was replaced by

$$
F_{\mathrm{IT}}=C \rho N_{b} L S_{\max }^{2} u^{2}\left(1-f^{2} / \omega^{2}\right)^{1 / 2} .
$$

The constant $C=1 /(4 \pi)$ in Eq. (3), equal to that of Nycander (2005), gives a reasonable consistency between $F_{\text {IT }}$ and the related dissipation rate along the A25 line (see section 3). For the latitudinal range of the A25 line, tidal waves at diurnal frequencies are bottom trapped $(\omega<f)$. The energy flux was thus restricted to the contributions of the semidiurnal frequencies $\left(\mathrm{M}_{2}\right.$, $\mathrm{S}_{2}, \mathrm{~N}_{2}, \mathrm{~K}_{2}$ ). The daily amplitude of the barotropic velocity used in Eq. (3) was computed from the TOPEX/ Poseidon Global Inverse Solution 7.2 (TPXO7.2) database (Egbert and Erofeeva 2002). Variable $N_{b}$ was computed from the CTD observations as the $160-\mathrm{m}$ mean buoyancy frequency [last segment of $N$ used in Eq. (1)]. The topographic scale $L$ and slope $S_{\max }$ were inferred from the global topography (Smith and Sandwell 1997). More complex parameterizations of the tidal flux exist (e.g., Nycander 2005; Pétrélis et al. 2006), but, as in Eq. (3), they all depend on the square of the velocity. Since we are interested in the relative variations of $F_{\text {IT }}$ over the years, which are mostly driven by variations in the barotropic tidal velocity, we then expect that the formulation Eq. (3) allows us to derive a reasonable estimate of the time variability in the tidal flux.

\section{6) MEAN FLOW TO TOPOGRAPHIC INTERNAL WAVE ENERGY CONVERSION RATE}

Topographic internal waves (also called lee waves or mountain waves) are generated when a mean current $\mathbf{U}_{\text {mean }}$ flows over some topographic roughness in a stratified fluid. The linear theory of internal wave generation in the presence of topography developed by Bell (1975) gives the energy conversion rate from the mean flow into topographic internal waves as

$$
F_{\mathrm{TW}}=\rho_{0} \int_{-\infty}^{+\infty} \int_{-\infty}^{+\infty} \frac{\omega}{\left(k^{2}+l^{2}\right)^{1 / 2}} P(k, l)\left(\omega^{2}-f^{2}\right)^{1 / 2}\left(N^{2}-\omega^{2}\right)^{1 / 2} d k d l
$$

where $\mathbf{k}=(k, l)$ is the horizontal wavevector, $P(k, l)$ is the spectrum of a topographic patch, and $\omega=\left(\mathbf{U}_{\text {mean }} \cdot \mathbf{k}\right)$ is the wave frequency. The wavenumber integration is done over the range of radiating waves for which $|f|<\omega<N$ and does not take into account topographic trapped waves. Aguilar and Sutherland (2006) showed that, when the vertical Froude number, defined as $\mathrm{Fr}_{v}=U_{\text {mean }} / N h$ (where $U_{\text {mean }}$ is the flow speed in the direction of the wavevector $\mathbf{k}$ ) is smaller than a critical value $\mathrm{Fr}_{c}$ (e.g., for large amplitude topography), the topography partially blocks the flow and reduces the conversion rate such that

$$
F_{\mathrm{TW}}^{c}=F_{\mathrm{TW}}\left(F r_{v} / F r_{c}\right)^{2}, \quad F r_{v}<F r_{c}
$$

For sinusoidal and triangular hills, Aguilar and Sutherland (2006) found $\mathrm{Fr}_{c}=0.75^{-1}$. This dependence was confirmed by numerical simulations with $\mathrm{Fr}_{c}=$ $0.7^{-1}$ (Nikurashin and Ferrari 2010). In this study we chose $\mathrm{Fr}_{c}=0.75^{-1}$.

To evaluate $F_{\mathrm{TW}}$ using (4) and (5), several ingredients are needed. Since we do not have time measurements to quantify the mean flow, the bottom LADCP velocity averaged within $500 \mathrm{~m}$ of the bottom is assumed to be representative of the mean flow. A constant buoyancy 
frequency of $5 \times 10^{-4} \mathrm{~s}^{-1}$, representative of the bottom stratification, is taken from the CTD stations located to the southeast of the Reykjanes Ridge where Eqs. (4) and (5) are applied. Given the latitudinal range of the events and the bottom-averaged LADCP velocity, waves can radiate if topographic horizontal length scales are in the range $0.5-8 \mathrm{~km}$. Such scales are usually not resolved by the global topographic map (Smith and Sandwell 1997). To characterize those horizontal scales $k$ along with their vertical scales $h$ at a given location, we used the single beam sounding along the transect that correctly resolves topographic scales larger than about $750 \mathrm{~m}$. Finally, $F_{\mathrm{TW}}$ was calculated using the observed scales $k$ and $h$ and assuming that the kilometer-scale hills have an axisymmetric sinusoidal shape, which fully determines $P(k, l)$ in Eq. (4).

\section{7) CONVERSION OF VERTICAL ENERGY FLUXES INTO DISSIPATION RATES}

In the following, $F_{\mathrm{IT}}$ and $F_{\mathrm{TW}}$ are converted to dissipation rates to quantify their respective contributions to the observed dissipation rates. This is done assuming that an average $q=30 \%$ of the energy is dissipated locally and that the vertical decay scale of the dissipation rate is about $1000 \mathrm{~m}$. While the latter can be diagnosed from our set of observations, we took a conservative value for $q$ that was estimated for the internal tide dissipation in the Brazil basin (St. Laurent and Garrett 2002). The morphology of the topography in our region of interest shares some similarities with that of the Brazil basin, both being located on the flank of the MidAtlantic Ridge. One can, however, expect some local variability in the parameter $q$ for the internal tide. To our knowledge, no such estimate of $q$ exists for topographic internal waves. Following Nikurashin and Ferrari (2013), we then chose the same value for both types of internal waves.

\section{Results}

\section{a. Mean dissipation rate and observed variability range}

The regions having the smallest 2002-12 mean dissipation rate, $\left\langle\varepsilon_{2002-2012}\right\rangle$, are located below $2000 \mathrm{~m}$ east of $21^{\circ} \mathrm{W}$ (distance from Portugal $d_{\text {Port }}<1450 \mathrm{~km}$ ) from the Iberian basin to the northwest of the Azores-Biscay Rise with values smaller than $1 \times 10^{-10} \mathrm{~W} \mathrm{~kg}^{-1}$ (Fig. 2a). Such small values are also found in the weakly stratified center of the Irminger basin, but this time at all depths. Those two deep regions are characterized by smooth topography as in the Brazil basin for which weak dissipation rates are also found (Polzin et al. 1997). The $\left\langle\varepsilon_{2002-2012}\right\rangle$ is enhanced at
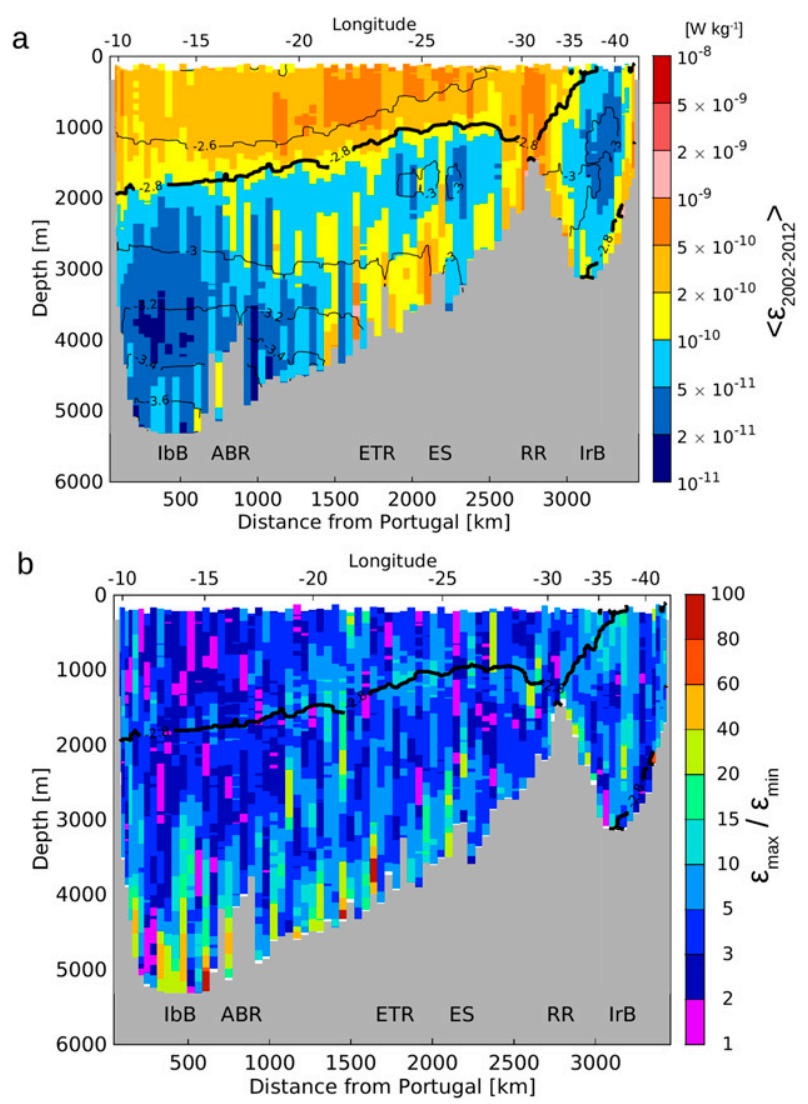

FIG. 2. (a) Turbulent kinetic energy dissipation rate $\left\langle\varepsilon_{2002-2012}\right\rangle$ $\left(\mathrm{W} \mathrm{kg}^{-1}\right)$ averaged from the six estimates of the repeated A25 hydrographic line. Black isolines depict the 2002-12 mean buoyancy frequency $N\left[\log _{10}(N), \mathrm{s}^{-1}\right.$, interval $\left.0.2 \mathrm{~s}^{-1}\right]$. The specific value $\log _{10}(N)=-2.8 \mathrm{~s}^{-1}$ is plotted as a thick black line. (b) Ratio of the local maximum to minimum dissipation rate over the period 200212. Color scales are nonlinear. IbB, Iberian Plain; ABR, AzoresBiscay Rise; ETR, East Thulean Rise; ES, Eriador Seamount; RR, Reykjanes Ridge; IrB, Irminger basin (see Fig. 1).

depth from $21^{\circ}$ to $26^{\circ} \mathrm{W}\left(1450 \mathrm{~km}<d_{\text {Port }}<2200 \mathrm{~km}\right)$. This region starts to the southwest of the East Thulean Rise (ETR; see Fig. 2) to Eriador Seamount (ES; Fig. 2 and map in Fig. 1). Because of the proximity of the Mid-Atlantic Ridge, it is characterized by an increase in topographic roughness having typical horizontal length scales of 3$40 \mathrm{~km}$ and vertical length scales of several hundreds of meters. There $\left\langle\varepsilon_{2002-2012}\right\rangle$ ranges over $1-20 \times 10^{-10}$ $\mathrm{W} \mathrm{kg}^{-1}$. Enhanced $\left\langle\varepsilon_{2002-2012}\right\rangle$ are also found farther north, on the flanks of the Reykjanes Ridge and on the Greenland slope, with maximum values of $5-10 \times 10^{-10} \mathrm{~W} \mathrm{~kg}^{-1}$. Those enhanced dissipation rates at depth vertically extend up to $500-1500 \mathrm{~m}$ above the bottom. In the upper ocean, $\left\langle\varepsilon_{2002-2012}\right\rangle$ is in the range $1-10 \times 10^{-10} \mathrm{~W} \mathrm{~kg}^{-1}$ for buoyancy frequencies $N>1.6 \times 10^{-3} \mathrm{~s}^{-1}$ (Fig. 2a, thick line). Those values are typically found in the main thermocline (e.g., Gregg 1989). 
To quantify the amplitude of the dissipation rate variability along the A25 line over the 2002-12 period, the ratio of the maximum to the minimum dissipation rate was calculated for each $160-\mathrm{m}$ vertical segment (Fig. 2b). Over most of the section this ratio is below 5 . Having in mind that the dissipation rate as estimated by Eq. (1) typically under- or overestimates the observed dissipation rate from microstructure by a factor of 4 (Ferron et al. 2014), the amplitude of the variability is remarkably small along this section for the late spring/ early summer period. In the thermocline, the ratio is slightly larger, ranging from 5 to 15 between $17^{\circ}$ and $26^{\circ} \mathrm{W}\left(1200 \mathrm{~km}<d_{\text {Port }}<2200 \mathrm{~km}\right)$, as well as in the Irminger Sea above $1500 \mathrm{~m}$ from $31^{\circ}$ to $39^{\circ} \mathrm{W}(2800 \mathrm{~km}<$ $d_{\text {Port }}<3200 \mathrm{~km}$ ). The largest variability (ratio from 5 to 100 ) is found at depth in regions where $\left\langle\varepsilon_{2002-2012}>\right.$ is small $\left(d_{\text {Port }}<1450 \mathrm{~km}\right.$ and in the Irminger Sea) or where it is enhanced $\left(1450 \mathrm{~km}<d_{\text {Port }}<2200 \mathrm{~km}\right)$. There is also more variability on the northwestern flank of the Reykjanes Ridge than on the southeastern one.

The year-by-year distribution of $\varepsilon_{\mathrm{G} 03}$ confirms that the isoline $N=1.6 \times 10^{-3} \mathrm{~s}^{-1}$ is a good predictor of the value $\varepsilon_{\mathrm{G} 03}=1 \times 10^{-10} \mathrm{~W} \mathrm{~kg}^{-1}$ that delimits the usually small dissipation rates in the deep ocean from the moderate ones in the thermocline (Fig. 3, thick black lines). The variability of $\varepsilon_{\mathrm{G} 03}$ in the Iberian basin (Fig. 2b) is mostly due to one occurrence of enhanced values observed in 2010 and to a lesser extent in 2008 (Fig. 3). At depth in the region $\left(1450 \mathrm{~km}<d_{\text {Port }}<2200 \mathrm{~km}\right), \varepsilon_{\mathrm{G} 03}$ is often enhanced locally around seamounts, with maximum values of $20-100 \times 10^{-10} \mathrm{~W} \mathrm{~kg}^{-1}$ reached in 2008 west of the $\operatorname{ETR}\left(22^{\circ} \mathrm{W}, d_{\text {Port }}=1640 \mathrm{~km}\right)$ and of $1-50 \times 10^{-10} \mathrm{~W} \mathrm{~kg}^{-1}$ reached in 2010 near ES. In the main thermocline, the largest $\varepsilon_{\mathrm{G} 03}\left(>5 \times 10^{-10} \mathrm{~W} \mathrm{~kg}^{-1}\right)$ are almost systematically located from the Azores-Biscay Rise to Eriador Seamount and above the Reykjanes Ridge. In the Irminger basin, the small dissipation rates of the upper water column tend to spread to the southeast with time, consistently with the migration of the isoline $N=1.6 \times$ $10^{-3} \mathrm{~s}^{-1}$ in that same direction (cf. the thick black line with thin white lines in Fig. 3). This is consistent with a strengthening of the winter deep convection observed since 2008 in the Irminger basin (Piron et al. 2016).

\section{b. Internal wave energy propagation and spectral distortion from the GM model}

The 2002-12 ratio of mean clockwise to mean counterclockwise variances shows a dominance of counterclockwise variance at depth with two exceptions: the Iceland basin to the northwest of Eriador Seamount and the center of the Irminger basin (Fig. 4). This suggests that the energy in the internal wave field preferentially propagates upward above the seafloor, which is compatible with an energy source at the bottom. Above the Reykjanes Ridge, a dominant upward energy propagation is also found from the bottom up to the near surface. Those features observed with the mean 2002-12 variances are representative of what happens on a year-by-year basis.

The distributions of the 2002-12 mean high $(\alpha)$ and mean low $(\beta)$ frequency factors show that they remain below a factor of three on most of the section (Figs. $5 a, b)$. This reveals that the observed level of internal wave field energy is close to the GM model level. This is particularly true for the upper ocean. This is consistent with the observation that the isolines $N=10^{-2.8} \mathrm{~s}^{-1}$ and $\varepsilon=1 \times 10^{-10} \mathrm{~W} \mathrm{~kg}^{-1}$ follow the same path (Figs. 2a, 3). Indeed, for a wave field close to the GM model, Eq. (1) mainly depends on $N / N_{0}$. In the vicinity of the bathymetry, departures from the GM model are stronger: $\alpha$ and $\beta$ both reach the range 5-7 with a few peak values around $10-12$ for $\alpha$ and around 8-10 for $\beta$.

Note that the low-frequency band $(f-2 f)$ includes the semidiurnal frequency. It is then not surprising that, close to the bathymetry, our observed energy level in the low-frequency band is higher than that of the GM model (i.e., $\beta>1$ ) since the latter does not take the spectral peak of the internal tide into account. Hibiya et al. (2012) also reported such large values of $\alpha$ and $\beta$ over the rough topography of the North Pacific. The spectral distortion as measured by the ratio $\beta / \alpha$ is moderate $(1 / 3<$ $\beta / \alpha<3$ ), even in the region where we observed stronger energy levels than the GM level (Fig. 5c). It is, however, worth noting that we systematically observe low values of $\beta / \alpha$ over the Reykjanes Ridge. This bias toward higher frequency possibly suggests that high-frequency waves are generated by interactions between the tide and the topography of the Reykjanes Ridge (Gerkema et al. 2006; Gerkema 2006; Pairaud et al. 2010). Low values of $\beta / \alpha$ are also found in the Iberian basin at and below the depth of the Mediterranean outflow water, between 1000 and $1800 \mathrm{~m}$. For an environment located below the Mediterranean outflow water, at a depth of $1400-1500 \mathrm{~m}$ in the Canary basin, van Haren and Gostiaux (2009) reported that the temperature spectra follow a $\omega^{-1}$ slope in the frequency domain for the internal wave band instead of the $\omega^{-2}$ slope of the GM model. Compared with the GM model, this amounts to having a larger contribution of the high-frequency band than of the low-frequency band. Indeed, for an internal wave field with a $\omega^{-1}$ slope, the ratio $\beta / \alpha$ can be readily expressed as

$$
\left(\frac{\beta}{\alpha}\right)_{\omega^{-1}}=\left(1-2 \frac{f}{N}\right) \frac{\log 2}{\log (N / 2 f)} .
$$



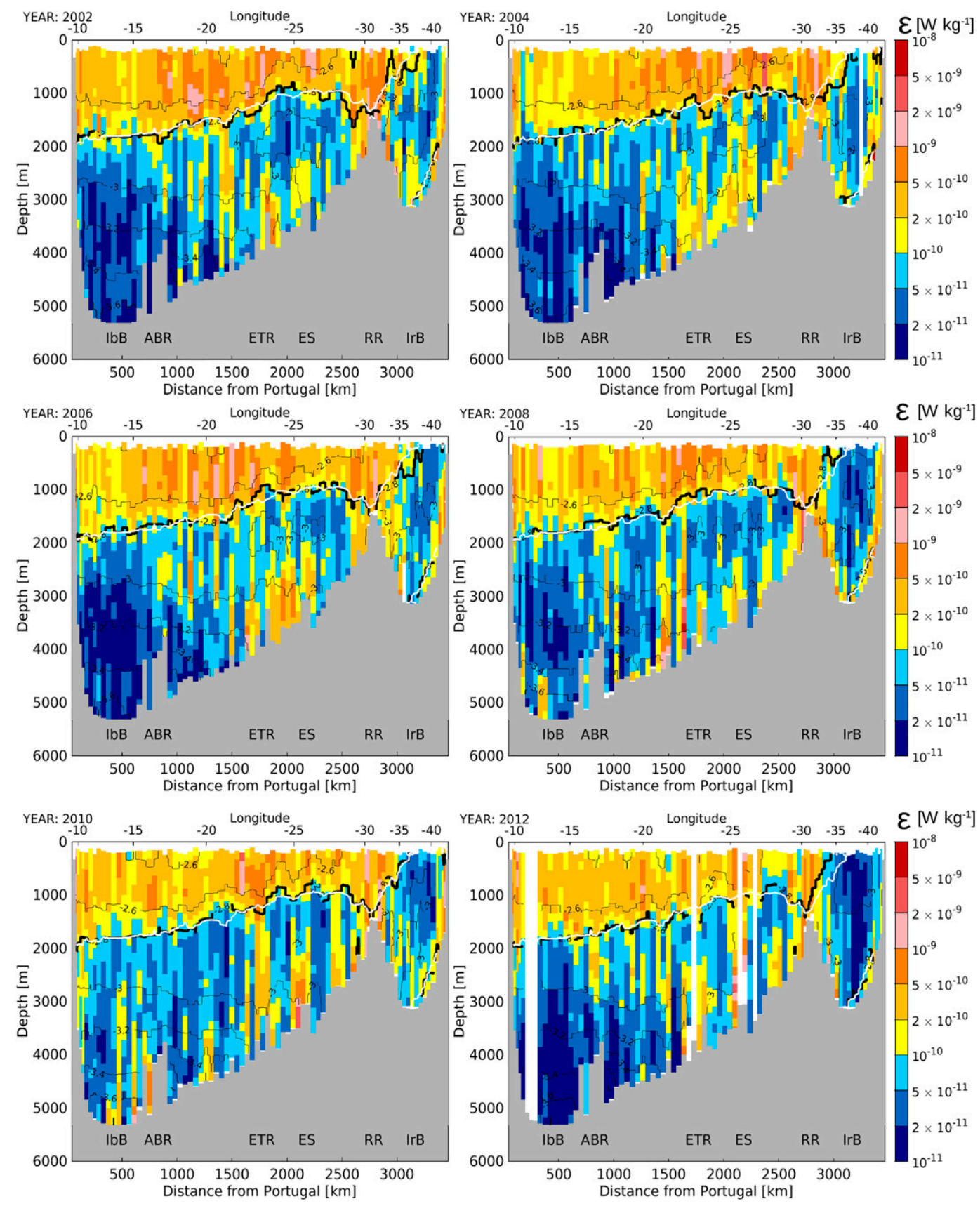

FIG. 3. Dissipation rate estimates of the turbulent kinetic energy (color, nonlinear scale, $\mathrm{W} \mathrm{kg}^{-1}$ ) along the repeated A25 hydrographic line for years 2002-12. White colors correspond to an absence of data or to the surface layer. Black isolines depict the buoyancy frequency $N\left[\log _{10}(N), \mathrm{s}^{-1}\right.$, interval $\left.0.2 \mathrm{~s}^{-1}\right]$. The specific value $\log _{10}(N)=-2.8 \mathrm{~s}^{-1}$ is plotted as a thick black line for the corresponding year and by the white line for its 2002-12 average.

Applying this relation to the Mediterranean water region delimited by $d_{\text {Port }}<1000 \mathrm{~km}$ (i.e., maximum latitudinal extent slightly to the northwest of the AzoresBiscay Rise) and to depths in the range $1000-1800 \mathrm{~m}$, with an averaged $N=2.1 \times 10^{-3} \mathrm{~s}^{-1}$ and $f=f\left(41.5^{\circ}\right)$, we get a typical $\beta / \alpha$ ratio of $3.8^{-1}$ for an internal wave field following a $\omega^{-1}$ slope. The observed $\beta / \alpha$ averaged over the same region is estimated at $3.1^{-1}$ (Fig. 5c). Thus, there is some consistency between our estimate and the $\omega^{-1}$ slope that van Haren and Gostiaux (2009) observed accurately with temperature sensors. They attributed the change in slope to the presence of density layering 


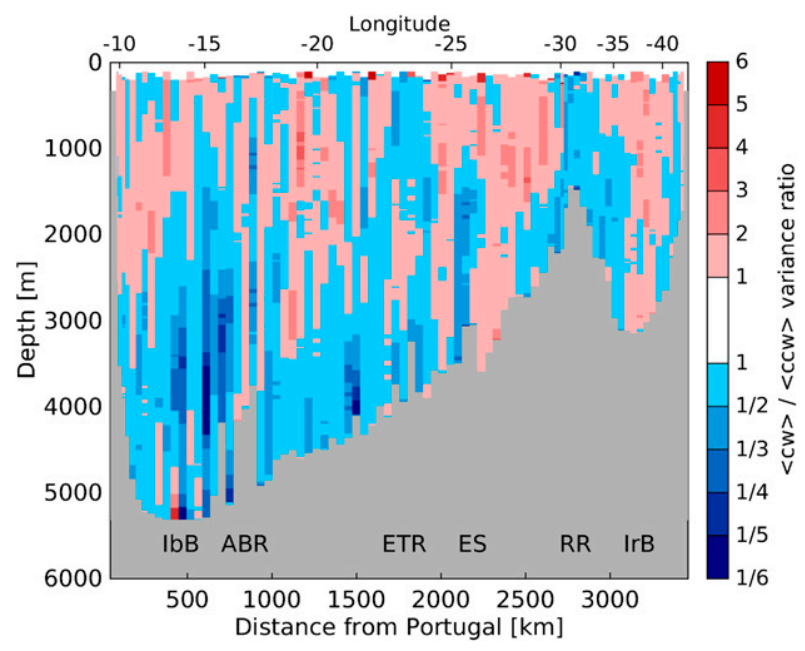

FIG. 4. Ratio of the 2002-12 mean clockwise variance to the 2002-12 mean counterclockwise variance.

and intermittency. Our CTD data also show a layered structure at and below the depth of the Mediterranean outflow.

\section{c. Relation between bottom dissipation rates, internal tide and topographic internal wave generations, and surface EKE}

To gain more insight about some possible mechanisms at the origin of the observed variability, dissipation rates $\varepsilon_{\mathrm{G} 03}$ were averaged within $500 \mathrm{~m}$ of the bottom $\left(\varepsilon_{\text {bottom }}\right)$ and within the upper thermocline between $100 \mathrm{~m}$ and $500 \mathrm{~m}$ depth $\left(\varepsilon_{\text {thermocline }}\right)$. It clearly appears that the time variability of $\varepsilon_{\text {bottom }}\left(\varepsilon_{\text {thermocline }}\right)$ lies within a factor of 4-5 (2-3) around its 2002-12 mean value (Figs. 6a,b). The interannual dispersion of $\varepsilon_{\text {bottom }}$ is usually remarkably weak in the Iberian, Iceland, and Irminger basins and stronger in the region from the ETR to ES, the Reykjanes Ridge, and the Greenland slope. The dispersion of $\varepsilon_{\text {thermocline }}$ follows the same pattern: it is enhanced between the ABR to the Reykjanes Ridge but reduced in the Iberian, Iceland, and Irminger basins.

The barotropic to baroclinic tidal energy conversion $F_{\text {IT }}$ as diagnosed from Eq. (3) shows an energy flux that varies because of the fortnight variability of the barotropic tide (Fig. 6c). Note that a flux $F_{\mathrm{IT}}=1 \mathrm{~mW} \mathrm{~m}^{-2}$ is equivalent to a dissipation rate $\varepsilon=2.3 \times 10^{-10} \mathrm{~W} \mathrm{~kg}^{-1}$, providing that about $30 \%$ of the wave energy is dissipated locally (St. Laurent and Garrett 2002) and that $\varepsilon$ decreases over a vertical length scale of about $1000 \mathrm{~m}$. Such a vertical length scale is observed on average for the bottom-enhanced $\varepsilon$ profiles of our dataset, although some departures exist (Fig. 7). The constant $C$ in Eq. (3) has a reasonable value since $F_{\mathrm{IT}}$, converted to a dissipation rate, is consistent with $\varepsilon_{\text {bottom }}$ over the Reykjanes
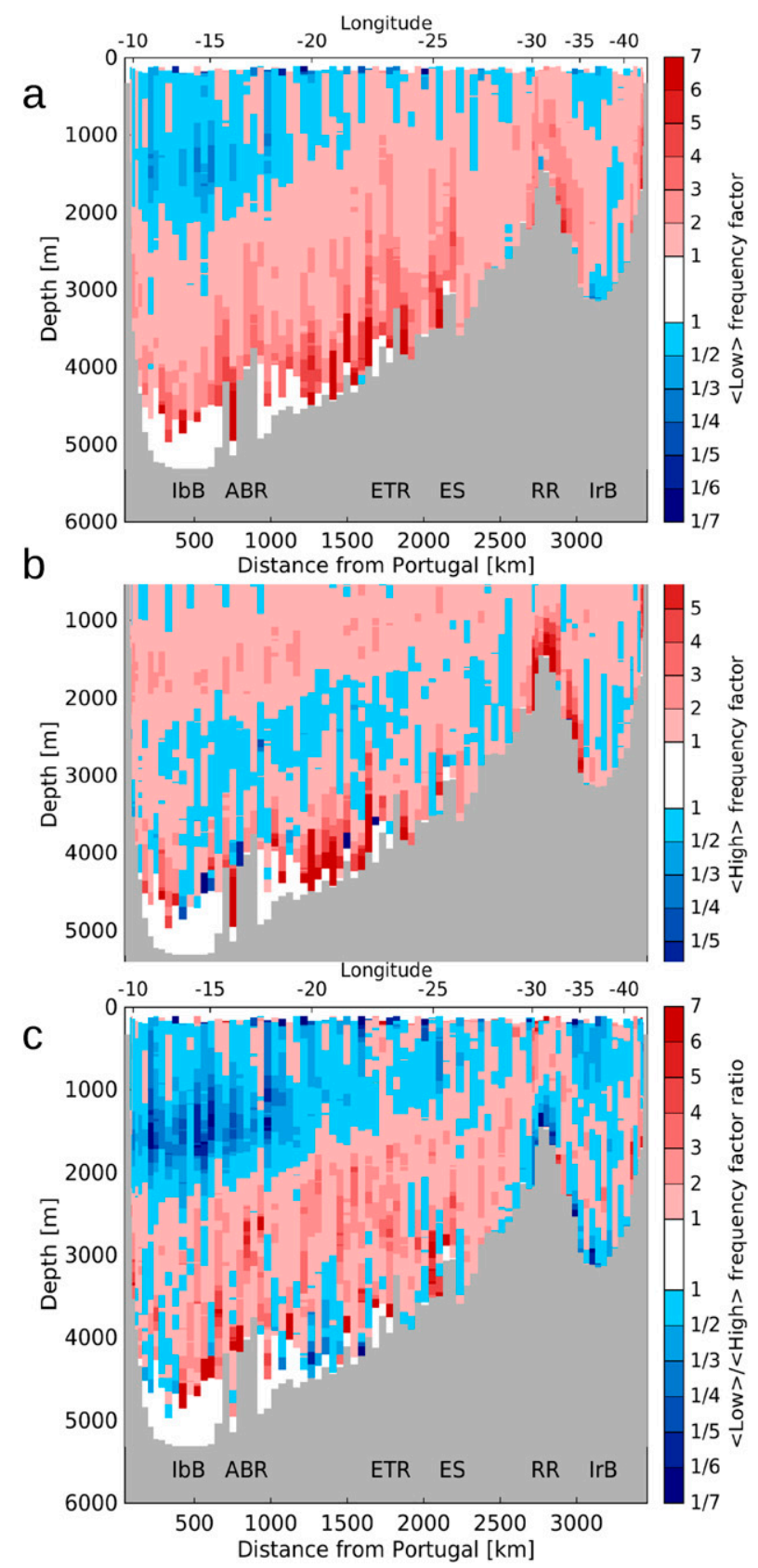

FIG. 5. (a) The 2002-12 mean low-frequency factor. (b) The 2002-12 mean high-frequency factor. (c) Ratio of the 2002-12 mean low- to high-frequency factors. A white area denotes a location where no estimate was computed (at the surface) or no physically meaningful estimate was found (at the bottom).

Ridge $\left(d_{\text {Port }}=2800 \mathrm{~km}\right)$ where a strong internal tide was observed (van Haren 2007). While some expected consistency is found in the location of enhanced $\varepsilon_{\text {bottom }}$ and enhanced $F_{\text {IT }}$ in terms of 2002-12 mean quantities (e.g., around ES, over the Reykjanes Ridge, and along the continental slopes), there is obviously a lack of consistency on a year-by-year basis. The interannual change in 
a

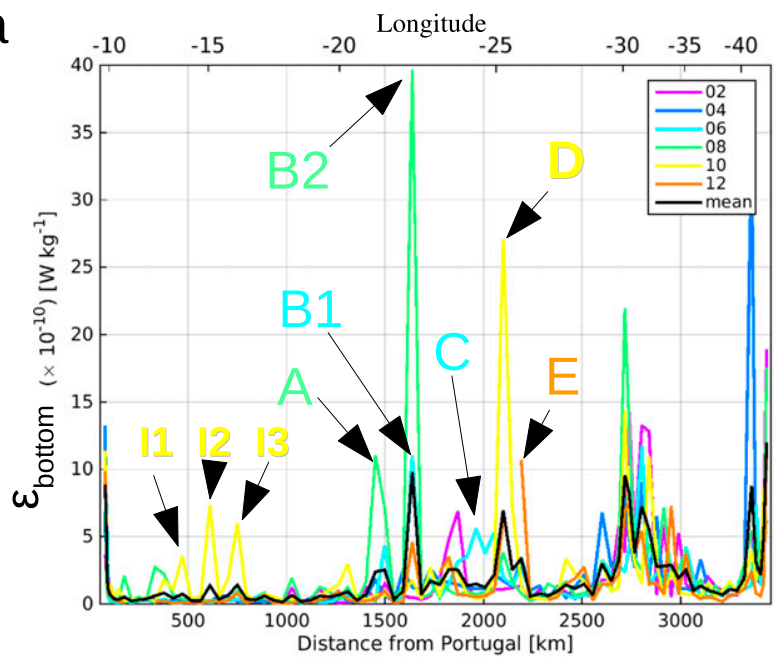

C

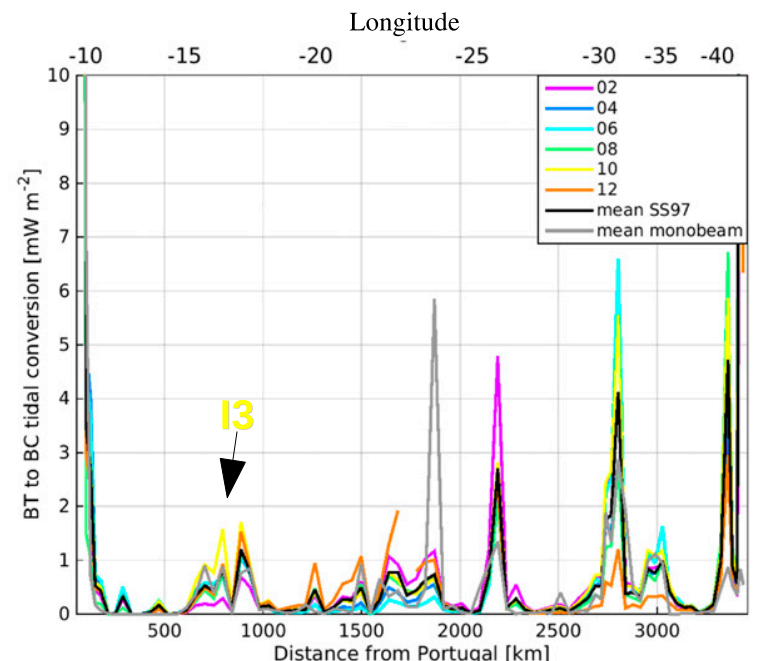

b

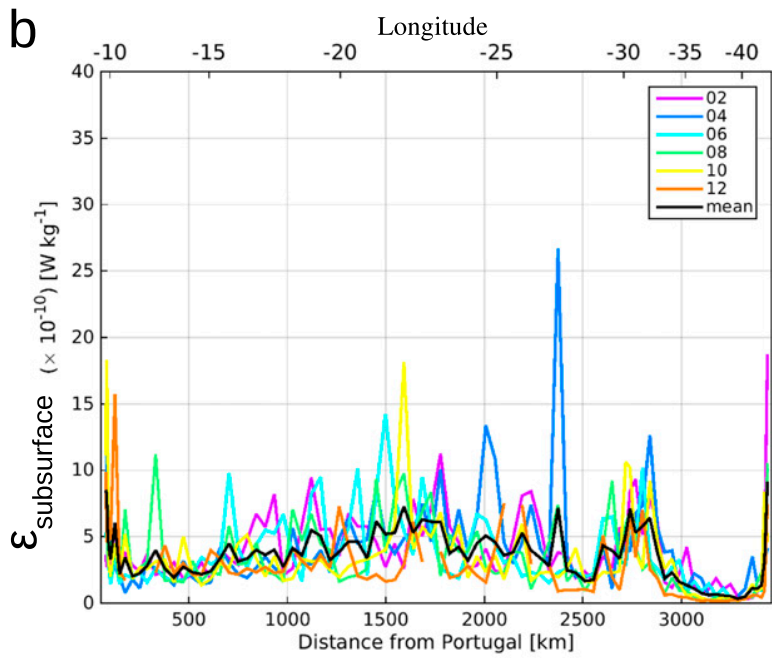

d

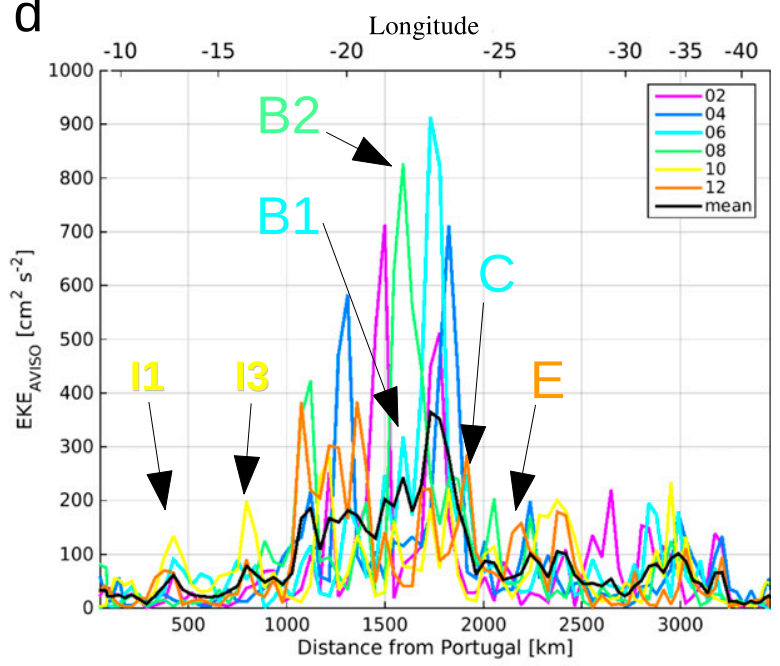

FIG. 6. Dissipation rates averaged (a) within $500 \mathrm{~m}$ of the bottom and (b) in the thermocline between 100 and $500 \mathrm{~m}$ depth. (c) Barotropic to baroclinic tidal energy conversion $\left(F_{\mathrm{IT}}\right)$. (d) Surface eddy kinetic energy interpolated at the station location. Each line is color coded by year and the 2002-12 mean is in black. The gray line in (c) is the 2002-12 mean tidal conversion estimated with the singlebeam bathymetry. Letters denote the location of nine events of large bottom dissipation rates discussed in the text.

tides may sign its influence on $\varepsilon_{\text {bottom }}$ at two locations: the Iberian basin, for which $F_{\mathrm{IT}}$ and $\varepsilon_{\text {bottom }}$ both have maximum values for year 2010 (Figs. 6a,c), and the summit of the Reykjanes Ridge at $d_{\text {Port }}=2800 \mathrm{~km}$, for which the events with the three largest dissipation rates have also the largest $F_{\text {IT }}$. Elsewhere, this lack of consistency is either due to $\varepsilon_{\text {bottom }}$ being related to more complex forcing mechanisms or to the signal-to-noise ratio being close to one. Indeed, the time variability of $\varepsilon_{\text {bottom }}$ lies within a factor of $4-5$, which is similar to the dispersion between fine- and microstructure estimates of $\varepsilon_{\mathrm{G} 03}$ (Ferron et al. 2014).

The surface eddy kinetic energy averaged over 2002-12 is enhanced by a factor of 3-7 between the
Azores-Biscay Rise to the ETR $\left(1000 \mathrm{~km}<d_{\text {Port }}<\right.$ $1900 \mathrm{~km}$ ) compared with an averaged observed value of $50 \mathrm{~cm}^{2} \mathrm{~s}^{-2}$ outside of this region (Fig. 6d, black line). To the north of the Azores-Biscay Rise, the surface EKE presents a large dispersion with peak values reaching 4 times their mean value and 4-10 times their median value. The most energetic region close to the ETR $\left(1500 \mathrm{~km}<d_{\text {Port }}<1900 \mathrm{~km}\right)$, with a 2002-12 mean EKE larger than $200 \mathrm{~cm}^{2} \mathrm{~s}^{-2}$, has also a mean $\varepsilon_{\text {thermocline }}$ among the largest of the transect $\left(\varepsilon_{\text {thermocline }}>5 \times 10^{-10} \mathrm{~W} \mathrm{~kg}^{-1}\right)$. On the Iceland basin side of the Reykjanes Ridge, the 2002-12 mean EKE is weak (about $40 \mathrm{~cm}^{2} \mathrm{~s}^{-2}$ between $2500 \mathrm{~km}<d_{\text {Port }}<$ $2800 \mathrm{~km}$ ), while on the Irminger basin side it is 


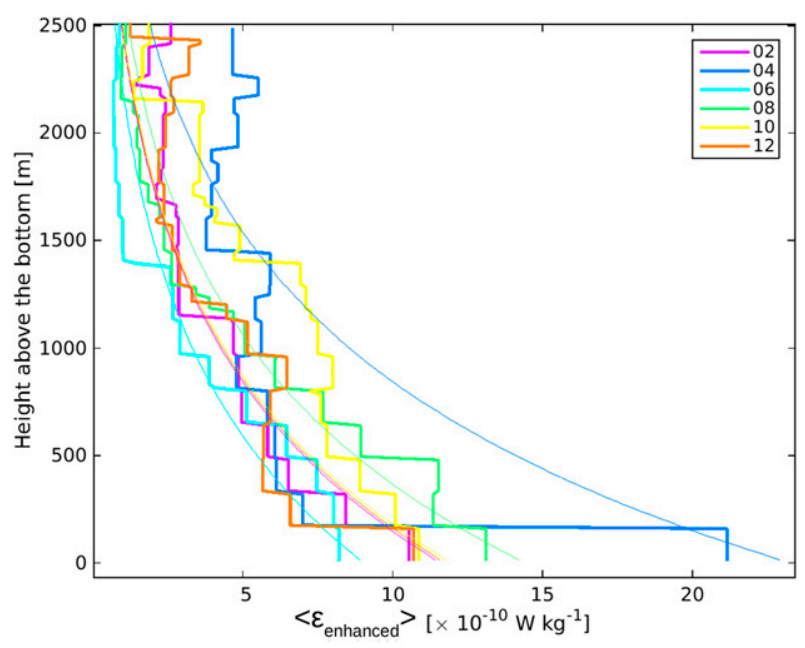

FIG. 7. Transect average of vertical dissipation rate profiles whose bottommost values are larger than $5 \times 10^{-10} \mathrm{~W} \mathrm{~kg}^{-1}$ (thick lines). The average was computed as a function of height above the bottom. The color depicts the transect year and the thin line is a fit of an exponential profile decaying with a 1000 -m vertical scale. Depending on the year, 8-12 profiles were averaged.

enhanced and reaches $100 \mathrm{~cm}^{2} \mathrm{~s}^{-2}$ with a strong interannual variability. On a year-by-year basis, no obvious relationship is found between the level of EKE and that of $\varepsilon_{\text {thermocline }}$ or $\varepsilon_{\text {bottom }}$ except for some energetic events.

Nine events having the largest departure in $\varepsilon_{\text {bottom }}$ from its median value calculated over the six transects were selected in order to study their characteristics. They are depicted by letters $\mathrm{A}$ to $\mathrm{E}$ in the region from the Azores-Biscay Rise to Eriador Seamount, and by I1 to I3 in the Iberian basin (Fig. 6, Table 2). All those events present an $\varepsilon_{\text {bottom }}$ that departs by at least a factor of 6 from the station median value (Table 2, column 7). The interpolated EKE at the location of the events A to
$\mathrm{E}$ is moderate (close to or larger than $200 \mathrm{~cm}^{2} \mathrm{~s}^{-2}$ ) to moderately strong $\left(>800 \mathrm{~cm}^{2} \mathrm{~s}^{-2}\right)$, except for event D (Table 2, column 4). For the events I1 to I3 located to the southeast, the EKE is less energetic and ranges from 50 to $140 \mathrm{~cm}^{2} \mathrm{~s}^{-2}$. At the exception of event $\mathrm{D}$, the EKE is larger than its median value by at least a factor of 2 (Table 2, column 8). The bottom velocity averaged within $500 \mathrm{~m}$ of the bottom frequently shows elevated values at the location of the events. From the AzoresBiscay Rise to Eriador Seamount, it ranges from 8 to $16 \mathrm{~cm} \mathrm{~s}^{-1}$ (Table 2, column 5). In the Iberian basin it reaches 4 to $11 \mathrm{~cm} \mathrm{~s}^{-1}$.

The largest observed peak in $\varepsilon_{\text {bottom }}$ of the 2002-12 period reaches $40 \times 10^{-10} \mathrm{~W} \mathrm{~kg}^{-1}$. It occurred during the year 2008 to the southeast of the ETR at $d_{\text {Port }}=$ $1640 \mathrm{~km}$ (Table 2, event B2). This peak in $\varepsilon_{\text {bottom }}$ is associated with a large peak in surface EKE that reaches $830 \mathrm{~cm}^{2} \mathrm{~s}^{-2}$ (Fig. 6d, Table 2). It is the second-largest surface EKE value observed on the transect for the 2002-12 period. Geostrophic eddy velocities show that the hydrographic station associated with the event is located on the northeastern edge of a cyclonic eddy (Fig. 8). At the same location, the second-largest peak in $\varepsilon_{\text {bottom }}\left(11 \times 10^{-10} \mathrm{~W} \mathrm{~kg}^{-1}\right)$ is observed in 2006 , for which we also observe the second-largest peak in EKE $\left(320 \mathrm{~cm}^{2} \mathrm{~s}^{-2}\right)$. The four other EKE values at $d_{\text {Port }}=$ $1640 \mathrm{~km}$ lie in the range $40-100 \mathrm{~cm}^{2} \mathrm{~s}^{-2}$ (Fig. 6d). Contrastingly, a tidal flux of $0.7 \mathrm{~mW} \mathrm{~m}^{-2}$ is diagnosed for 2008 and a smaller one $\left(0.3 \mathrm{~mW} \mathrm{~m}^{-2}\right)$ for the year 2006 at $d_{\text {Port }}=1640 \mathrm{~km}$. The largest tidal flux for this area occurs in 2012 and reaches $1.3 \mathrm{~mW} \mathrm{~m}^{-2}$. Thus, the change in $\varepsilon_{\text {bottom }}$ at $d_{\text {Port }}=1640 \mathrm{~km}$ is more consistent with the change in EKE level than with that of the tidal flux.

To evaluate the order of magnitude of the energy flux from the mean flow into topographic internal waves

TABLE 2. Bottom-intensified dissipation rate events for which $\varepsilon_{\text {bottom }} / \varepsilon_{\text {median }}>5$. Events A to E are located between the Azores-Biscay Rise and the Reykjanes Ridge. The three less turbulent I events are located in the Iberian basin. Surface EKE interpolated at the location and time of the events and estimated from AVISO gridded sea surface height. Magnitude of the LADCP velocities and dissipation rates averaged within $500 \mathrm{~m}$ of the bottom ( $\left\langle U_{\mathrm{LADCP}}\right\rangle_{\text {bottom }}$ and $\varepsilon_{\text {bottom }}$, respectively); ratio of $\varepsilon_{\text {bottom }}$ (EKE) to its median value is calculated from the six transects (Figs. 6a and 6d, respectively).

\begin{tabular}{|c|c|c|c|c|c|c|c|}
\hline $\begin{array}{l}\text { Year/ } \\
\text { event }\end{array}$ & $\begin{array}{l}\text { Location on the } \\
\text { transect }\left(d_{\text {Port }}, \mathrm{km}\right)\end{array}$ & Lat, lon & $\operatorname{EKE}\left(\mathrm{cm}^{2} \mathrm{~s}^{-2}\right)$ & $\begin{array}{c}\left\langle U_{\text {LADCP }}\right\rangle_{\text {bottom }} \\
\left(\mathrm{cm} \mathrm{s}^{-1}\right)\end{array}$ & $\varepsilon_{\text {bottom }}\left(\times 10^{-10} \mathrm{~W} \mathrm{~kg}^{-1}\right)$ & $\begin{array}{l}\varepsilon_{\text {bottom }} / \\
\varepsilon_{\text {median }}\end{array}$ & $\underset{\text { median }}{\mathrm{EKE} / \mathrm{EKE}}$ \\
\hline 2008/A & 1450 & $48.41^{\circ} \mathrm{N}, 21.14^{\circ} \mathrm{W}$ & 200 & 9 & 11 & 16 & 2 \\
\hline 2006/B1 & 1640 & $49.91^{\circ} \mathrm{N}, 22.31^{\circ} \mathrm{W}$ & 320 & 8 & 11 & 6 & 4 \\
\hline 2008/B2 & 1640 & $49.91^{\circ} \mathrm{N}, 22.31^{\circ} \mathrm{W}$ & 830 & 16 & 40 & 22 & 10 \\
\hline $2006 / \mathrm{C}$ & 1960 & $52.52^{\circ} \mathrm{N}, 24.36^{\circ} \mathrm{W}$ & 250 & 20 & 6 & 8 & 4 \\
\hline 2010/D & 2100 & $53.64^{\circ} \mathrm{N}, 25.24^{\circ} \mathrm{W}$ & 50 & 14 & 27 & 14 & 1 \\
\hline 2012/E & 2190 & $54.39^{\circ} \mathrm{N}, 25.83^{\circ} \mathrm{W}$ & 180 & 10 & 11 & 8 & 3 \\
\hline 2010/I1 & 470 & $41.38^{\circ} \mathrm{N}, 13.89^{\circ} \mathrm{W}$ & 110 & 6 & 4 & 23 & 2 \\
\hline 2010/I2 & 610 & $42.28^{\circ} \mathrm{N}, 15.06 \mathrm{~W}$ & 50 & 4 & 7 & 35 & 3 \\
\hline 2010/I3 & 750 & $43.18^{\circ} \mathrm{N}, 16.24^{\circ} \mathrm{W}$ & 140 & 11 & 6 & 18 & 4 \\
\hline
\end{tabular}




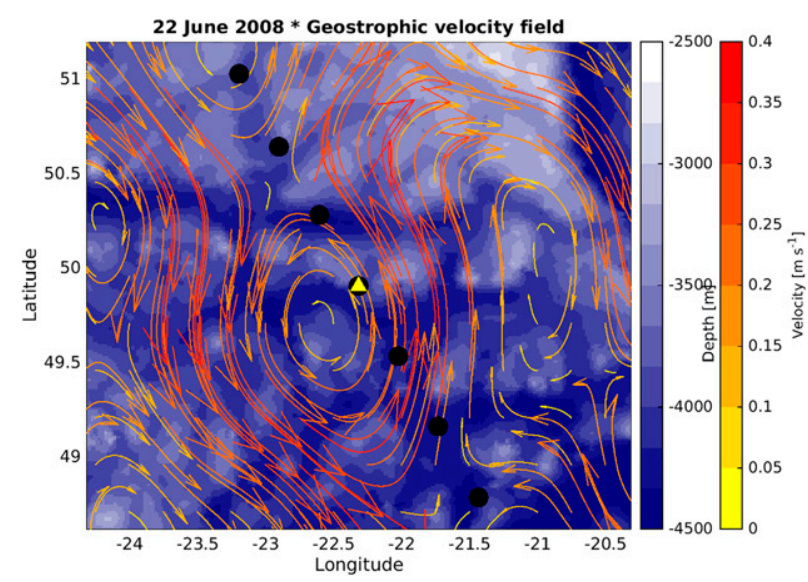

FIG. 8. Geostrophic eddy velocity field (arrows) from sea surface height maps at the time of the largest 2002-12 bottom dissipation rate event B2 (yellow triangle) that occurred in 2008 with bathymetry (Smith and Sandwell 1997) colored in blue.

using Eqs. (4) and (5), the characteristic height and length scale of appropriate hills (i.e., such that $|f|<$ $\omega<N)$ surrounding the location of each events are given in Table 3. For most of the events, the vertical Froude number is large (i.e., $\mathrm{Fr}_{v}^{-1}<0.75$ ) so that the energy conversion Eq. (4) derived from linear theory can be used. For events A, B1, and I2, the conversion rate is reduced according to Eq. (5) (values in parentheses in Table 3). The ratio $\omega / f$ varies in the range 1.1-3.4 while $\omega / N$ is in the range $0.25-0.7$. The dissipation rate associated with the energy flux from the mean flow into topographic internal waves $F_{\mathrm{TW}}$ is compared with that associated with the internal tide $F_{\mathrm{IT}}$ and to the observed 500-m bottom-averaged dissipation rate (last three columns of Table 3). Two comments are worth noting. First, the values of $\varepsilon_{\mathrm{TW}}$ are consistent with those of $\varepsilon_{\text {bottom }}$ within a factor of $2-3$, except for events B1 and I2 for which $\varepsilon_{\mathrm{TW}} \ll \varepsilon_{\text {bottom. }}$ For these two events, the blocking effect by the topography decreases the conversion rate by $60 \%$ for event B1 and by $96 \%$ for event I2. Second, except for event I3 in the Iberian basin and event $\mathrm{E}$ along Eriador Seamount, $\varepsilon_{\mathrm{IT}}$ is much smaller by an order of magnitude than $\varepsilon_{\text {bottom. The dataset thus }}$ suggests that the strong events of bottom dissipation rates observed to the southeast of the Reykjanes Ridge are rather sustained by the interaction of mean currents with the topography than by the internal tide. In this region, eddies drift slowly with time scales much larger than an inertial period. Moreover, Mercier and Colin de Verdière (1985) showed that these eddies have as much energy in the first baroclinic mode as in the barotropic mode. When they interact with the topography, these eddies provide a source for the mean currents at depth, as shown by the consistent increase in bottom dissipation rates and surface EKE for most of the studied events.

\section{Summary and discussion}

We have examined the time variability in the dissipation rate along the A25 Greenland-Portugal transect repeated every 2 years. Applying a finescale parameterization that uses CTD and LADCP profiles, we showed that the dissipation rate is usually remarkably stable in time, at least not larger than the uncertainty of the method. However, this is not the case for some stations located to the southeast of the Iceland basin where the time variability of bottom dissipation rates is largely increased. We used estimates of the energy flux into the internal tide and topographic internal waves in order to discriminate between various processes leading to a possible time variability in the turbulent mixing. It was shown that if the tides are a major source for the mixing

TABLE 3. Parameters used to estimate the energy conversion rate $F_{\mathrm{TW}}$ from the mean flow $U_{\text {mean }}$ into topographic internal waves of intrinsic frequency $\omega$. Characteristic wavelength $\lambda$ and peak-to-peak height $h$ of topographic hills surrounding the location of the event as measured from single-beam soundings. The vertical $\left(\mathrm{Fr}_{v}\right)$ and horizontal $\left(\mathrm{Fr}_{h}\right)$ Froude numbers used a constant buoyancy frequency $N=$ $5 \times 10^{-4} \mathrm{~s}^{-1}$. Variable $f$ is the Coriolis frequency at the event location. Dissipation rates $\varepsilon_{\mathrm{TW}}, \varepsilon_{\mathrm{bottom}}$, and $\varepsilon_{\mathrm{IT}}$ were estimated from $F_{\mathrm{TW}}$ [Eqs. (4) or (5), values in parentheses, when $\mathrm{Fr}_{v}^{-1}>0.75$ ], from finescale parameterization [Eq. (1)], and from $F_{\mathrm{IT}}$ [Eq. (2)], respectively.

\begin{tabular}{|c|c|c|c|c|c|c|c|c|c|c|}
\hline $\begin{array}{l}\text { Year/ } \\
\text { event }\end{array}$ & $\begin{array}{c}\lambda \\
(\mathrm{km})\end{array}$ & $\begin{array}{c}H \\
(\mathrm{~m})\end{array}$ & $\begin{array}{c}U_{\text {mean }} \\
\left(\mathrm{cm} \mathrm{s}^{-1}\right)\end{array}$ & $\begin{array}{c}\operatorname{Fr}_{v}^{-1}=N h / \\
U_{\text {mean }}\end{array}$ & $\omega / f$ & $\mathrm{Fr}_{h}=\omega / N$ & $F_{\mathrm{TW}}\left(\mathrm{mW} \mathrm{m}^{-2}\right)$ & $\begin{array}{c}\varepsilon_{\mathrm{TW}} \\
\left(\times 10^{-10} \mathrm{~W} \mathrm{~kg}^{-1}\right)\end{array}$ & $\begin{array}{c}\varepsilon_{\text {bottom }} \\
\left(\times 10^{-10} \mathrm{~W} \mathrm{~kg}^{-1}\right)\end{array}$ & $\varepsilon_{\mathrm{IT}}\left(\times 10^{-10} \mathrm{~W} \mathrm{~kg}^{-1}\right)$ \\
\hline $2008 / \mathrm{A}$ & 3 & 200 & 9 & 1.1 & 1.7 & 0.4 & (4) & (9) & 11 & 0.6 \\
\hline 2006/B1 & 4 & 200 & 8 & 1.2 & 1.1 & 0.25 & (1) & (2) & 11 & 0.6 \\
\hline 2008/B2 & 4 & 200 & 16 & 0.6 & 2.2 & 0.5 & 27 & 64 & 40 & 2 \\
\hline $2006 / \mathrm{C}$ & 3 & 50 & 20 & 0.1 & 3.6 & 0.8 & 2 & 5 & 6 & 0.2 \\
\hline 2010/D & 4 & 150 & 14 & 0.5 & 1.9 & 0.4 & 11 & 26 & 27 & 0.2 \\
\hline 2012/E & 2 & 150 & 10 & 0.7 & 2.6 & 0.6 & 11 & 26 & 11 & 5 \\
\hline 2010/I1 & 3 & 140 & 6 & 0.4 & 1.3 & 0.6 & 2 & 5 & 4 & 0.6 \\
\hline 2010/I2 & 2 & 300 & 4 & 3.7 & 1.3 & 0.25 & $(0.3)$ & $(0.7)$ & 7 & 0.2 \\
\hline 2010/I3 & 2 & 100 & 11 & 0.5 & 3.4 & 0.7 & 6 & 14 & 6 & 2 \\
\hline
\end{tabular}


around the Reykjanes Ridge, topographic internal waves generated by mean currents seem to be at the origin of strong dissipative events to the southeast of the Iceland basin. In the following, we present and discuss uncertainties and limitations associated with the approach.

The finescale parameterization provides dissipation rate estimates that were shown to be, at $90 \%$ over the whole transect, within a factor of 3-4 larger or smaller than microstructure estimates (Ferron et al. 2014). The geographical distribution of this dispersion sometimes exhibits a random character but also local biases. Local biases may not be persistent in time if the underlying dynamics leading to small-scale turbulence and kinetic energy dissipation evolves in time. This "natural" dispersion of the finescale method is relatively low if one considers that dissipation rates typically evolve over six orders of magnitude $\left(10^{-11}\right.$ to $\left.10^{-6} \mathrm{~W} \mathrm{~kg}^{-1}\right)$ in the open ocean. One can argue that it is relatively large for the temporal variability that we found on this transect. That is why we have only discussed a few events of enhanced dissipation rate above the bottom that stand out of the natural dispersion of the finescale method. Those events depart from the median by at least a factor of 6. Most of those events are located in a region between the south of the East Thulean Rise and Eriador Seamount. In this region, the finescale parameterization tends to systematically underestimate the microstructure dissipation rate by a factor of 2 , for moderate dissipation rates $\left(1-5 \times 10^{-10} \mathrm{~W} \mathrm{~kg}^{-1}\right)$, to 5 , for enhanced dissipation rates $\left(10-50 \times 10^{-10} \mathrm{~W} \mathrm{~kg}^{-1}\right.$; Ferron et al. 2014). The finescale parameterization produces a low-biased estimate but with a smaller dispersion. Therefore, the events of enhanced dissipation rates that were identified can be reasonably related to physical mechanisms rather than to uncertainties in the finescale parameterization.

The energy flux from the barotropic tide into the internal tide that we used has several limitations. Indeed, Eq. (3) does not take into account the orientation of the tidal ellipse relative to the topographic gradient (e.g., Nycander 2005). We also did not apply the correction for finite depth that tends to suppress wave generation when the horizontal topographic scale $L$ is longer than the horizontal wavelength $L_{c}$ associated with the first vertical mode (Llewellyn Smith and Young 2002). Suppression occurs when $L>$ $L_{c}=N D /\left(\omega^{2}-f^{2}\right)^{1 / 2}$, where $D$ is the ocean depth and $L_{c}$ varies from $80 \mathrm{~km}$ at the southern part of the transect to $40 \mathrm{~km}$ around the summit of the Reykjanes Ridge. The effect of this correction for the semidiurnal tide will be small here since $L_{c}$ is always larger than $L$ along the transect.
On the other hand, the unresolved topography of the global map (Smith and Sandwell 1997), that is, scales shorter than about $20 \mathrm{~km}$, as well as bottom-trapped waves associated with diurnal tidal frequencies could each add a contribution to Eq. (3). To assess the importance of the former, the 2002-12 mean tidal flux was computed with the single-beam sounding topography that resolves horizontal scales larger than about $750 \mathrm{~m}$ only in the direction of the transect. It clearly appears that the two estimates of the 2002-12 mean tidal fluxes are consistent, with those estimated from the global topography being usually slightly larger than those from the single-beam sounding (Fig. 6c, black and gray curves, respectively). Only one hill to the southeast of Eriador Seamount exhibits a single-beam-based tidal flux significantly larger (by a factor of 8 ) than that of the global lower-resolution topography (Fig. $6 \mathrm{c} ; d_{\text {Port }}=$ $1850 \mathrm{~km}$ ). The single-beam sounding shows that this hill is slightly supercritical to semidiurnal tidal waves, that is, $H / L<\omega / N$. Thus, the associated $6 \mathrm{~mW} \mathrm{~m}^{-2}$ tidal flux is an upper bound of what the hill can produce. Elsewhere on the section, the topography is subcritical. We then do not expect a significant contribution from unresolved topographic scale to the tidal flux for this transect. Falahat and Nycander (2015) quantified the energy flux from the barotropic tide to bottom-trapped tidal waves. They showed that this energy conversion is usually weak compared to the energy input into freely propagating waves. Regionally, the contribution can, however, be significant, as mentioned for the diurnal internal tide around the Kuril Islands (see also Niwa and Hibiya 2011). In our region of interest, since the kinetic energy in the diurnal components of the barotropic tide represents only $10 \%$ of the semidiurnal component kinetic energy, we do not expect that diurnal trapped waves contribute significantly to our estimated energy flux into the internal tide. Semidiurnal waves can also be bottom trapped whenever the maximum critical trapping frequency $\omega_{T}=N \sin \alpha$ is larger than the semidiurnal frequency, where $\alpha$ is the angle of the bottom slope to the horizontal (Rhines 1970). This would increase the ratio of internal wave energy dissipated locally to that radiated away from the generation region. However, apart from over the slopes of the continental shelf, $\omega_{T}$ is always smaller than the semidiurnal frequency along the transect.

The estimate of the energy flux into topographic internal waves is based on kilometer-scale topographic features present in our single-beam sounding record. This record is only one dimensional while a twodimensional high-resolution map would be necessary. We have assumed that the observed relevant scale of the hills located in a reasonable distance (maximum of a few 
TABLE 4. Annual mean and interannual range of the number of days per year for which the local surface EKE is in the range 200$600 \mathrm{~cm}^{2} \mathrm{~s}^{-2}$ or larger than $600 \mathrm{~cm}^{2} \mathrm{~s}^{-2}$ at each event location and for the period 2002-12. Annual mean and interannual range of the expected bottom dissipation rates within $500 \mathrm{~m}$ of the bottom are due to topographic internal waves $\varepsilon_{\mathrm{TW}}$, assuming that an EKE of $200-$ $600 \mathrm{~cm}^{2} \mathrm{~s}^{-2}$ produces a dissipation rate of $10 \times 10^{-10} \mathrm{~W} \mathrm{~kg}^{-1}$ and that an EKE larger than $600 \mathrm{~cm}^{2} \mathrm{~s}^{-2}$ produces a dissipation rate of $40 \times$ $10^{-10} \mathrm{~W} \mathrm{~kg}^{-1}$. Annual mean dissipation rate within $500 \mathrm{~m}$ of the bottom due to internal tides $\varepsilon_{\mathrm{IT}}$.

\begin{tabular}{lcccc}
\hline \hline Event & $\begin{array}{c}\text { EKE 200-600 cm } \mathrm{s}^{-2} \\
\text { annual mean (min-max) }\end{array}$ & $\begin{array}{c}\text { EKE }>600 \mathrm{~cm}^{2} \mathrm{~s}^{-2} \text { annual } \\
\text { mean (min-max) }\end{array}$ & $\begin{array}{c}\text { Expected } \varepsilon_{\mathrm{TW}}\left(\times 10^{-10} \mathrm{~W} \mathrm{~kg}^{-1}\right) \\
\text { annual mean (min-max) }\end{array}$ & $\begin{array}{c}\text { Estimated } \varepsilon_{\mathrm{IT}}\left(\times 10^{-10} \mathrm{~W} \mathrm{~kg}^{-1}\right) \\
\text { annual mean }\end{array}$ \\
\hline A & $107(9-211)$ & $12(0-36)$ & $4(0.2-10)$ & 0.7 \\
B1/B2 & $155(50-251)$ & $21(0-88)$ & $7(1-17)$ & 2 \\
C & $102(14-178)$ & $5(0-45)$ & $3(0.4-10)$ & 0.3 \\
D & $130(38-270)$ & $9(0-46)$ & $5(1-12)$ & 0.2 \\
E & $44(8-81)$ & $1(0-15)$ & $1(0.2-4)$ & 8 \\
I1 & $1(0-12)$ & $0(0-0)$ & $0.03(0-0.3)$ & 0.5 \\
I2 & $2(0-23)$ & $0(0-0)$ & $0.05(0-0.6)$ & 0.3 \\
I3 & $10(0-75)$ & $0(0-0)$ & $0.3(0-2)$ & 1 \\
\hline
\end{tabular}

kilometers) from the station were typical of the area. Other topographic small-scale hills that were not sampled by the single-beam survey certainly exist and can change the estimated flux. Furthermore, without this two-dimensional high-resolution topography, we also had to arbitrarily choose a shape for the hills. We chose an axisymmetric sinusoidal shape. For instance, an assumed axisymmetric sinusoidal hill would underestimate by a factor of 3 the real flux if the hill was actually a sinusoidal ridge.

Despite all these limitations, we see that the selected events, all located in a region of rough topography to the southeast of the Iceland basin, share some common points: 1) a horizontal length scale of the relevant topography that frequently lies between 2 and $4 \mathrm{~km}$ for a vertical length scale of 100 to $200 \mathrm{~m}, 2$ ) a bottomintensified current whose magnitude is $O(10) \mathrm{cm} \mathrm{s}^{-1}$ associated with the subtropical-subpolar intergyre of moderate surface intensified eddy kinetic energy that varies in the range $200-800 \mathrm{~cm}^{2} \mathrm{~s}^{-2}$, and 3) an estimated energy flux into topographic internal waves that is most of the time an order of magnitude larger than the estimated semidiurnal tidal flux. Unfortunately, we do not have time measurements of bottom currents to characterize their frequency modulation. Given the geographical and dynamical context of the region, it seems reasonable to assume that the energy of the bottomenhanced currents is fed by the subsurface mesoscale as in other areas (Gille et al. 2000; Liang and Thurnherr 2012; St Laurent et al. 2012). A high-resolution model clearly showed that the link between surface-intensified eddying geostrophic flows, bottom-enhanced velocities, topographic internal gravity waves, and energy dissipation is of primary importance for the energetic of the Antarctic Circumpolar Current (Nikurashin et al. 2013). Observations of turbulent mixing also support this scenario in the Southern Ocean (Heywood et al. 2002;
Naveira Garabato et al. 2004; Sloyan 2005; Sheen et al. 2013).

The region of the Northeastern Atlantic located between the Iceland basin and the Azores-Biscay Rise exhibits a smaller and less constant eddy kinetic energy level than that of the Southern Ocean or that of the Gulf Stream. But even in this less energetic part of the ocean, this set of observations suggests the existence of the same link between surface-intensified eddying geostrophic flows, bottom-enhanced velocities, and kinetic energy dissipation. The surface eddy kinetic energy level of the region varies in time over three orders of magnitude. According to altimeter data, it is on average larger by $25 \%$ during the months of January-June than it is between August and December for the 200212 period. One may then question the representativeness of our estimates derived from summer instantaneous profiles. To get an idea of the annual mean value of the bottom dissipation rate due to topographic internal waves along the transect, we calculated the number of days per year for which the surface eddy kinetic energy level is in the range $200-600 \mathrm{~cm}^{2} \mathrm{~s}^{-2}$ and larger than $600 \mathrm{~cm}^{2} \mathrm{~s}^{-2}$ for the period 2002-12. Based on our observations, if we assign a 500-m bottom-averaged dissipation rate of $0 \mathrm{~W} \mathrm{~kg}^{-1}$ to an EKE smaller than $200 \mathrm{~cm}^{2} \mathrm{~s}^{-2}$, of $10 \times$ $10^{-10} \mathrm{~W} \mathrm{~kg}^{-1}$ to an EKE in the range $200-600 \mathrm{~cm}^{2} \mathrm{~s}^{-2}$, and of $40 \times 10^{-10} \mathrm{~W} \mathrm{~kg}^{-1}$ to an EKE larger than $600 \mathrm{~cm}^{2} \mathrm{~s}^{-2}$, one can very crudely estimate the annual mean dissipation rate due to topographic internal waves and its range of variation (Table 4). This annual mean expected dissipation rate is usually weak in the Iberian basin and increases while moving north of the Azores-Biscay Rise. An annual mean value of 3-7 $\times$ $10^{-10} \mathrm{~W} \mathrm{~kg}^{-1}$ is expected at the location of events $\mathrm{A}$, (B1/B2), C, and D where the EKE level is the largest of the transect. This annual mean value increases by a factor 2-3 for years having the largest EKE levels. This 
simple calculation favors the idea that the contribution to the annual mean dissipation rate of the generation of topographic internal waves will dominate that of the internal tide at the location of the events A to D (columns 4-5, Table 4). For all the other event locations, the dissipation rate associated with the internal tide is expected to be larger than that of topographic internal waves, although the latter has the same order of magnitude for the most energetic years. We can also expect to get larger energy fluxes into topographic internal waves and dissipation rates westward of our transect since the EKE level is larger there while the topography remains rough.

It is not clear whether the global estimates of the energy flux into topographic internal waves calculated from the bottom velocities of a global model at $1 / 8^{\circ}$ horizontal resolution (Nikurashin and Ferrari 2011) are able to capture the flux that we diagnose in our study. This model probably underestimates the bottom velocities associated with mesoscale-bathymetry interactions since, at this resolution, the smaller (but poorly) resolved scales are about $20 \mathrm{~km}$ at $50^{\circ} \mathrm{N}$. This scale is similar to the large-scale roughness of the region. We can anticipate that new configurations with at least $1 / 50^{\circ}$ resolution will give more accurate estimates of enhanced bottom velocities to indirectly estimate the energy flux into topographic internal waves, but it would still not resolve the generation of topographic internal waves that would require a topography and a model with at least $1 / 200^{\circ}(500 \mathrm{~m})$ of resolution.

Acknowledgments. We thank all crew members of the R/V Thalassa, R/V Maria S. Merian, and R/V Sarmiento de Gamboa. We also wish to thank all technicians and engineers who contributed to the CTD/ LADCP data acquisition and processing (A. Billant, P. Branellec, J.-P. Gouillou, M. Hamon, C. Kermabon, C. Lagadec, P. Le Bot, S. Leizour, O. Ménage, O. Péden, and the Unidad de Tecnología Marina). The OVIDE project was supported by IFREMER, CNRS/INSU and the National Program LEFE. B. Ferron, H. Mercier, and T. Huck were supported by the French National Center for Scientific Research (CNRS), P. Lherminier and $\mathrm{V}$. Thierry by the French Institute for Marine Science (Ifremer), and F. Kokoszka by the European University of Brittany. Aida F. Ríos was funded by the Spanish Ministry of Economy and Competitiveness (BES-2014-070449) through the BOCATS project (CTM2013-41048-P). The CATARINA cruise was supported the Spanish Ministry of Sciences and Innovation cofunded by the Fondo Europeo de Desarrollo Regional 2007-2012 (FEDER) through the CATARINA project (CTM2010-17141). We thank the anonymous reviewers for their useful comments and Aurélien Ponte for some helpful discussions on internal wave dynamics.

\section{REFERENCES}

Aguilar, A., and B. R. Sutherland, 2006: Internal wave generation from rough topography. Phys. Fluids, 18, 066603, doi:10.1063/ 1.2214538 .

Bell, T., 1975: Topographically generated internal waves in the open ocean. J. Geophys. Res., 80, 320-327, doi:10.1029/ JC080i003p00320.

Cairns, J. L., and G. O. Williams, 1976: Internal wave observations from a midwater float, 2. J. Geophys. Res., 81, 1943-1950, doi:10.1029/JC081i012p01943.

Egbert, G. D., and S. Y. Erofeeva, 2002: Efficient inverse modeling of barotropic ocean tides. J. Atmos. Oceanic Technol., 19, 183-204, doi:10.1175/1520-0426(2002)019<0183:EIMOBO>2.0.CO;2.

Falahat, S., and J. Nycander, 2015: On the generation of bottomtrapped internal tides. J. Phys. Oceanogr., 45, 526-545, doi:10.1175/JPO-D-14-0081.1.

Fer, I., A. K. Peterson, and J. E. Ullgren, 2014: Microstructure measurements from an underwater glider in the turbulent Faroe Bank Channel overflow. J. Atmos. Oceanic Technol., 31, 1128-1150, doi:10.1175/JTECH-D-13-00221.1.

Ferrari, R., and C. Wunsch, 2009: Ocean circulation kinetic energy reservoirs, sources and sinks. Annu. Rev. Fluid Mech., 41, 253-282, doi:10.1146/annurev.fluid.40.111406.102139.

Ferron, B., F. Kokoszka, H. Mercier, and P. Lherminier, 2014: Dissipation rate estimates from microstructure and finescale internal wave observations along the A25 GreenlandPortugal OVIDE line. J. Atmos. Oceanic Technol., 31, 25302543, doi:10.1175/JTECH-D-14-00036.1.

Garrett, C., and W. Munk, 1975: Space-time scales of internal waves: A progress report. J. Geophys. Res., 80, 291-297, doi:10.1029/JC080i003p00291.

Gerkema, T., 2006: Internal-wave reflection from uniform slopes: Higher harmonics and Coriolis effects. Nonlinear Processes Geophys., 13, 265-273, doi:10.5194/npg-13-265-2006.

- C. Staquet, and P. Bouruet-Aubertot, 2006: Non-linear effects in internal-tide beams, and mixing. Ocean Modell., 12, 302-318, doi:10.1016/j.ocemod.2005.06.001.

Gille, S. T., M. M. Yale, and D. T. Sandwell, 2000: Global correlation of mesoscale ocean variability with seafloor roughness from satellite altimetry. Geophys. Res. Lett., 27, 1251-1254, doi:10.1029/1999GL007003.

Gonella, J., 1972: A rotary-component method for analysing meteorological and oceanographic vector time series. Deep-Sea Res. Oceanogr. Abstr., 19, 833-846, doi:10.1016/0011-7471(72)90002-2.

Green, J. A. M., and J. Nycander, 2013: A comparison of tidal conversion parameterizations for tidal models. J. Phys. Oceanogr., 43, 104-119, doi:10.1175/JPO-D-12-023.1.

Gregg, M. C., 1989: Scaling turbulent dissipation in the thermocline. J. Geophys. Res., 94, 9686-9689, doi:10.1029/JC094iC07p09686.

— T. B. Sanford, and D. P. Winkel, 2003: Reduced mixing from the breaking of internal waves in equatorial ocean waters. Nature, 422, 513-515, doi:10.1038/nature01507.

Heywood, K. J., A. C. Naveira Garabato, and D. P. Stevens, 2002: High mixing rates in the abyssal Southern Ocean. Nature, 415, 1011-1014, doi:10.1038/4151011a.

Hibiya, T., N. Furuichi, and R. Robertson, 2012: Assessment of finescale parameterizations of turbulent dissipation rates near mixing hotspots in the deep ocean. Geophys. Res. Lett., 39, L24601, doi:10.1029/2012GL054068.

Jayne, S. R., 2009: The impact of abyssal mixing parameterizations in an ocean general circulation model. J. Phys. Oceanogr., 39, 1756-1775, doi:10.1175/2009JPO4085.1. 
_ over rough topography. Geophys. Res. Lett., 28, 811-814, doi:10.1029/2000GL012044.

Johnston, T. M. S., D. L. Rudnick, G. S. Carter, R. E. Todd, and S. T. Cole, 2011: Internal tidal beams and mixing near Monterey Bay. J. Geophys. Res., 116, C03017, doi:10.1029/ 2010JC006592.

Leaman, K. D., 1976: Observations on the vertical polarization and energy flux of near-inertial waves. J. Phys. Oceanogr., 6, 894-908, doi:10.1175/1520-0485(1976)006<0894:OOTVPA $>2.0 . C O ; 2$.

Liang, X., and A. M. Thurnherr, 2012: Eddy-modulated internal waves and mixing on a midocean ridge. J. Phys. Oceanogr., 42, 1242-1248, doi:10.1175/JPO-D-11-0126.1.

Llewellyn Smith, S. G., and W. R. Young, 2002: Conversion of the barotropic tide. J. Phys. Oceanogr., 32, 1554-1566, doi:10.1175/ 1520-0485(2002)032<1554:COTBT $>2.0 . C O ; 2$.

$\longrightarrow$, and 2003: Tidal conversion at a very steep ridge. J. Fluid Mech., 495, 175-191, doi:10.1017/S0022112003006098.

Mercier, H., and A. Colin de Verdière, 1985: Space and time scales of mesoscale motions in the eastern North Atlantic. J. Phys. Oceanogr., 15, 171-183, doi:10.1175/1520-0485(1985)015<0171: SATSOM $>2.0 . \mathrm{CO} ; 2$.

Moum, J. N., R. C. Lien, A. Perlin, J. D. Nash, M. C. Gregg, and P. J. Wiles, 2009: Sea surface cooling at the equator by subsurface mixing in tropical instability waves. Nat. Geosci., 2, 761-765, doi:10.1038/ngeo657.

Naveira Garabato, A., K. Polzin, B. King, K. Heywood, and M. Visbeck, 2004: Widespread intense turbulent mixing in the Southern Ocean. Science, 303, 210-213, doi:10.1126/ science.1090929.

Nikurashin, M., and R. Ferrari, 2010: Radiation and dissipation of internal waves generated by geostrophic flows impinging on small-scale topography: Theory. J. Phys. Oceanogr., 40, 10551074, doi:10.1175/2009JPO4199.1.

— strophic flows into internal lee waves in the deep ocean. Geophys. Res. Lett., 38, L08610, doi:10.1029/2011GL046576.

$\longrightarrow$, and —, 2013: Overturning circulation driven by breaking internal waves in the deep ocean. Geophys. Res. Lett., $\mathbf{4 0}$, 3133-3137, doi:10.1002/grl.50542.

_ , G. Vallis, and A. Adcroft, 2013: Routes to energy dissipation for geostrophic flows in the Southern Ocean. Nat. Geosci., 6, 48-51, doi:10.1038/ngeo1657.

Niwa, Y., and T. Hibiya, 2011: Estimation of baroclinic tide energy available for deep ocean mixing based on three-dimensional global numerical simulations. J. Oceanogr., 67, 493-502, doi:10.1007/s10872-011-0052-1.

Nycander, J., 2005: Generation of internal waves in the deep ocean by tides. J. Geophys. Res., 110, C10028, doi:10.1029/2004JC002487.

Pairaud, I., C. Staquet, J. Sommeria, and M. Mahdizadeh, 2010: Generation of harmonics and sub-harmonics from an internal tide in a uniformly stratified fluid: Numerical and laboratory experiments. IUTAM Symposium on Turbulence in the Atmosphere and Oceans, D. Dritschel, Ed., IUTAM Book Series, Vol. 28, Springer, 51-62, doi:10.1007/978-94-007-0360-5_5.

Palmer, M. R., G. R. Stephenson, M. E. Inall, C. Balfour, A. Düsterhus, and J. A. M. Green, 2015: Turbulence and mixing by internal waves in the Celtic Sea determined from ocean glider microstructure measurements. J. Mar. Syst., 144, 57-69, doi:10.1016/j.jmarsys.2014.11.005.

Pétrélis, F., S. Llewellyn Smith, and W. R. Young, 2006: Tidal conversion at a submarine ridge. J. Phys. Oceanogr., 36, 10531071, doi:10.1175/JPO2879.1.

Piron, A., V. Thierry, H. Mercier, and G. Caniaux, 2016: Argo float observations of basin-scale deep convection in the Irminger Sea during winter 2011-2012. Deep-Sea Res. I, 109, 76-90, doi:10.1016/j.dsr.2015.12.012.

Polzin, K. L., J. M. Toole, and R. W. Schmitt, 1995: Finescale parameterization of turbulent dissipation. J. Phys. Oceanogr., 25, 306328, doi:10.1175/1520-0485(1995)025<0306:FPOTD>2.0.CO;2.

- —, J. R. Ledwell, and R. W. Schmitt, 1997: Spatial variability of turbulent mixing in the abyssal ocean. Science, 276, 93-96, doi:10.1126/science.276.5309.93.

Rhines, P. B., 1970: Edge-, bottom-, and Rossby waves in a rotating stratified fluid. Geophys. Fluid Dyn., 1, 273-302, doi:10.1080/ 03091927009365776.

Sheen, K. L., and Coauthors, 2013: Rates and mechanisms of turbulent dissipation and mixing in the Southern Ocean: Results from the Diapycnal and Isopycnal Mixing Experiment in the Southern Ocean (DIMES). J. Geophys. Res. Oceans, 118, 2774-2792, doi:10.1002/jgrc.20217.

Sloyan, B. M., 2005: Spatial variability of mixing in the Southern Ocean. Geophys. Res. Lett., 32, L18603, doi:10.1029/ 2005GL023568.

Smith, W. H. F., and D. T. Sandwell, 1997: Global sea floor topography from satellite altimetry and ship depth soundings. Science, 277, 1956-1962, doi:10.1126/science.277.5334.1956.

St. Laurent, L., and C. Garrett, 2002: The role of internal tides in mixing the deep ocean. J. Phys. Oceanogr., 32, 2882-2899, doi:10.1175/1520-0485(2002)032<2882:TROITI >2.0.CO;2.

_ A. C. Naveira Garabato, J. R. Ledwell, A. M. Thurnherr, J. M. Toole, and A. J. Watson, 2012: Turbulence and diapycnal mixing in Drake Passage. J. Phys. Oceanogr., 42, 2143-2152, doi:10.1175/JPO-D-12-027.1.

van Haren, H., 2007: Inertial and tidal shear variability above Reykjanes Ridge. Deep-Sea Res. I, 54, 856-870, doi:10.1016/ j.dsr.2007.03.003.

_ , and L. Gostiaux, 2009: High-resolution open-ocean temperature spectra. J. Geophys. Res., 114, C05005, doi:10.1029/ 2008JC004967.

Visbeck, M., 2002: Deep velocity profiling using lowered acoustic Doppler current profilers: Bottom track and inverse solutions. J. Atmos. Oceanic Technol., 19, 794-807, doi:10.1175/ 1520-0426(2002)019<0794:DVPULA > 2.0.CO;2. 